\title{
DESENVOLVIMENTO SUSTENTÁVEL E SUAS CONTRADIÇÕES
}

\section{SUSTAINABLE DEVELOPMENT AND CONTRADICTIONS}

\author{
Pollyana Luz Macedo da Silva \\ Universidade Federal Fluminense \\ E-mail: pollyanaluzmello@hotmail.com
}

\begin{abstract}
RESUMO
O trabalho aqui exposto apresenta reflexões sobre o processo de exploração, desmatamento e usurpação da vida orgânica e inorgânica da natureza, que afirma sinais de esgotamento nas últimas décadas. A intensificação da deteriorização do meio ambiente torna-se visível a partir da construção de uma sociedade de consumo descartável. Diante do exposto cabem as seguintes questões que serão explanadas ao longo do trabalho: Como conciliar desenvolvimento sustentável num sistema altamente destrutivo como o capitalista? Como harmonizar alto grau de desenvolvimento das forças produtivas com efetiva preservação ambiental e de habitat? Como manter ecossistemas naturais com elevado índice de urbanização e progresso tecnológico? Há verdadeiramente acordo entre modo de produção baseado na lógica capitalista e modo de manutenção da natureza? Esses e outros questionamentos serão abordados no decorrer do trabalho.
\end{abstract}

Palavras-chave: Capitalismo; Sustentabilidade; Meio Ambiente.

\begin{abstract}
The work proposed here presents reflections on the process of exploitation, deforestation and encroachment of the organic life of nature that says signs of exhaustion in recent decades. The intensification of the deterioration of the environment becomes visible from the construction of a society of disposable consumption. Given the above fit the following issues that they are covered throughout the work: How to reconcile sustainable development in a highly destructive capitalist system like? How to harmonize high degree of development of productive forces with effective environmental conservation and habitat? How to maintain natural ecosystems with high rates of urbanization and technological progress? There truly is agreement between the capitalist mode of production based on the logic and nature of maintenance mode? These and other questions will be addressed in this work.
\end{abstract}

Key-Words:Capitalism;Sustainability; Environment.

\section{INTRODUÇÃO}

O trabalho aqui exposto apresenta reflexões a respeito da questão ambiental e desenvolvimento sustentável no modo de produção capitalista. Cabe a seguinte questão que será explanada ao longo deste trabalho: Como conciliar desenvolvimento sustentável num sistema altamente destrutivo como o capitalista? Como harmonizar alto grau de desenvolvimento das forças produtivas com efetiva preservação ambiental e de habitat? Como 
manterecossistemas naturais com elevado índice de urbanização e progresso tecnológico? Há verdadeiramente acordo entre modo de produção baseado na lógica capitalista emodo de manutenção da natureza?

Esses e outros questionamentos serão abordados no decorrer do trabalho, juntamente com inflexões críticas a respeito do modo como a sociedade atual trabalha com esse tema que é suscitado e reivindicado nos últimos anos.

O tema do meio ambiente se destacou no cenário público através da Conferência de Estocolmo em 1972. A maneira como foi abordada essa temática de acordo com a lógica capitalista e como se referencia atualmente são assuntos tratados neste texto. Partindo de uma análise de incompatibilidade entre desenvolvimento sustentável e capitalismo, o presente trabalho trás abordagens que fundamentam tal perspectiva de forma a esclarecer tal posição.

\section{DESENVOLVIMENTO SUSTENTÁVEL X CAPITALISMO: UMA EQUAÇÃO POSSÍVEL?}

Durante todo o processo de desenvolvimento e progresso do sistema capitalista, não deixando de segundo plano a intensificação da produtividade e das forças produtivas que o mesmo engendrou ao longo dos anos,é relevante destacar a despreocupação que determinado modo de produção fez-se referente à sua matéria-prima: a natureza. Sendo este último o objeto de trabalho que compõem os meios de produção, que juntamente com a força de trabalho como meio vivo que move todo o processo de trabalho, é essencial a sua preservação como forma de manutenção para a sobrevivência de um modo de produção típico de uma sociedade que se baseia na exploração, não só do homem, mas do meio ambiente que vive esse homem.

Todo o processo de exploração, desmatamento e usurpação da vida orgânica e inorgânica da natureza, afirma sinais de esgotamento nas últimas décadas ao qualindica alarmante esvaziamento de seus recursos. A 
deteriorização do meio ambiente torna-se visível quando se observa ao redor a sociedade que se construiu desde finais da década de 1970.

Como conseqüênciada crise na década de 1970 em diante, desponta com enorme relevância "questões ambientais" tais como, "aumento da poluição do ar e da água, a destruição da camada de ozônio, o acúmulo de lixo, o esgotamento dos recursos naturais não renováveis, o avanço da desertificação etc."1(SILVA, 2010, p. 163).

Antes de eclodir a crise, o nível do progresso tecnológico, baseado em reformas desenvolvimentistas - fato que se intensificou no Brasil durante o período autocrático burguês - era bastante elevado com um discurso de autos rendimentos e que com esse empreendimento todos ganhariam, tanto a classe burguesa revertida em lucros quanto a classe subalterna com empregos e renda. Mas esse modelo de desenvolvimento se defronta com problemas não previstos em seus planos: a progressiva devastação do planeta.

Com o modelo neoliberal como alavanca para outro sistema de desenvolvimento do capital, agora o mesmo põem em pauta questões que antes eram tratadas em última instância. O lema da questão ambiental é absorvido pelo capital em uma roupagem de "desenvolvimento sustentável" sem relevar e questionar o tipo de sociedade que provocou tal nível de destruição com o desenvolvimentismo adotado no pós-guerra. Silva explicita como surge todo esse processo:

Na realidade, a formulação Desenvolvimento Sustentável representa uma tentativa de oferecer respostas à problemática do meio ambiente a partir de uma crítica às teorias desenvolvimentistas, hegemônicas no pós-guerra, sem, no entanto, inscrevê-las no contexto da crítica ao modo capitalista de produção; em outras palavras, trata-se de uma tentativa de articular expansão capitalista e utilização racional dos recursos naturais, crescimento econômico, respeito ao meio ambiente e redução da pobreza. (SILVA, 2010, p. 167)

Os recursos naturais do planeta se esgotam - principalmente os recursos não renováveis - à medida do desenvolvimento e progresso

\footnotetext{
${ }^{1}$ Questõesambientaisestasretratadas no documentário "The story of stuff" - História das Coisas - com Annie Leonard, produzidopela "Funders workgroup for sustainable production and comsuption".
} 
capitalista. A disputa por tais recursos se torna primordial para o capital atualmente, e com isso aumenta a tensão entre países que detém territórios geográficos estratégicos onde se situam tais recursos. O conflito entre países se trava eminente à medida que fontes como essas se localizam fundamentalmente em países periféricos.

Interessante destacar as causas da questão ambiental segundo os "ideólogos do capital", que se situa não no modo como a sociedade capitalista se produz e reproduz, mas na forma desordenada de crescimento populacional e ocupação humana, tendo, portanto, consequências exógenas à lógica do capital. Com este argumento verifica-se uma total ausência de responsabilidade de países de industrialização avançada, pois a taxa de natalidade nestes países é baixa se comparado ao de países com industrialização tardia, culpabilizando, assim, os países pobres pela desigualdade social e pobreza geradas. Portanto, "dado o caráter finito dos recursos naturais, o estilo de vida da população dos países industrializados não poderia ser estendido a toda a humanidade, sob pena de colocar em risco as condições de existência na Terra". (SILVA, 2010, p. 169).

Verifica-se um processo perverso da industrialização de países periféricos, pois os mesmos são vistos pelos países centrais como territórios onde suas filiais se instalam - através do processo de terceirização, quarteirização, etc. - para obterem vantagens e lucros exorbitantes através de força de trabalho barata disponível em demasia e incentivos dos próprios governantes locais para a entrada dos mesmos em seu território. Atrelado a essa conjuntura está a vantagem de países periféricos terem legislações mais brandas para questões ambientais, sendo assim, a mesma absorve indústrias poluidoras de produção.

Segundo princípios neoliberais, o mercado seria o grande impulsionador do desenvolvimento sustentável, apesar de todos os malefícios trazidos por esse sistema. Mas verifica-se que "ainda que mudanças na base técnica sejam fundamentais, nem economia ecológica nem a economia ambiental realizam uma crítica à economia de 'livre mercado". Conclui Silva, que assim "faz-se 
necessário reiterar a impossibilidade de se assegurar uma existência sustentável no planeta sob a ordem burguesa" (SILVA, 2010, p. 175).

Um evento emblemático que marcou este assunto foi a Agenda 21 global, que tinha como objetivo vincular "o desenvolvimento social e econômico à proteção e melhoria do meio ambiente", que abarca uma ideologia capitalista acerca do tema aqui estudado. Com o discurso ambiental também tendo um enfoque ético, Silva ressalta que,

\begin{abstract}
O discurso do Desenvolvimento Sustentável se assenta em forte apelo ético. No entanto, dada a ausência de uma organização social que promova a utilização coletiva dos recursos naturais, assim, como a geração de detritos, verifica-se o aprofundamento do fosso entre 0 discurso ético e a realidade objetiva, tendo em vista que a dimensão ética integra o interesse universal, relativa ao gênero humano como totalidade, enquanto a dinâmica societária regida pelo capital implica uma lógica particularista, individualista por natureza (SILVA, 2010, p. 180).
\end{abstract}

Portanto a própria dinâmica da sociedade burguesa é incompatível com a sustentabilidade de um ecossistema saudável. O documentário "História das coisas" retrata bem essa impossibilidade ao relatar que desde a extração, passando pela produção, distribuição, consumo até o tratamento do lixo, esse sistema impossibilita a renovação dos materiais utilizados devidoser uma sistema linear e altamente destrutivo sem recomposição dos materiais produzidos pelo mesmo.

O capitalismo trouxe o desenvolvimento, porém houve um grande aumento na degradação do meio ambiente, causando uma crise ambiental, difundindo o pensamento sustentável, causando uma destruição em massa, similar ao movimento que o capital fez ao decorrer histórico. Sabe-se que a expansão econômica é a condição inalienável da acumulação capitalista e segundo Marx (1985) "a produção aparece como objetivo do homem e a riqueza como objetivo de produção"(SILVA, 2010, p.183).

Silva e Mota explicitam que a crise do capital, na década de 1970, "impulsionou a busca de alternativas menos predatórias dos recursos naturais e das potencialidades humanas", porém o mal estar com os modelos de desenvolvimento se deu muito antes disso, já no pós-guerra, com o modelo 
Keynesiano, o modelo desenvolvimentista-periférico, aprofundou o canal entre os países centrais e da periferia, causado mais desigualdade social, desemprego, aumentando o número de sem-terra, entre outras formas de coerção, causando um esgotamento dos recursos naturais não renováveis, colocando em pauta o debate da "questão ambiental" e do desenvolvimento.

Mota enfatiza que nos anos 90 o debate em torno do desenvolvimento sustentável estava presente em acordos internacionais, mas que a temática desenvolvimento passava pelo processo de "avanço do pensamento neoliberal e no determinismo dos ajustes das políticas de ajuste macro econômico."

O domínio do homem sobre a natureza aumentou com o processo de industrialização. O mito do progresso e do crescimento econômico propagado pelos ideólogos neoliberais levou a humanidade a conviver com padrões insustentáveis de produção e consumo e a condições desiguais no acesso aos recursos naturais que viabilizam a atividade econômica.

Neste contexto, a sustentabilidade apresentou-se como "princípio ético e moral", por imputar à atual geração a responsabilidade pela preservação das condições de reprodução das gerações futuras. Assim,

\footnotetext{
O caráter sedutor e encantador da proposição reside no apelo à preservação da natureza, ao enfrentamento da desigualdade social e ao comprometimento individual e coletivo da sociedade com o meio ambiente, ignorando as determinações históricas do processo destrutivo (MOTA \& SILVA, 2009, p. 39).
}

Em diversas conferências mundiais tratando do meio ambiente, nações propuseram importantes acordos para buscar um desenvolvimento sustentável. Mota e Silva questionam a Comissão Econômica para a America Latina e o Caribe (CEPAL), pois esse formulador e cumpridor de um papel de destaque nesse processo do desenvolvimento sustentável, sabe que o crescimento econômico foi o grande causador da destruição do meio ambiente, porém não o contesta, ao contrário, defende a adoção de normas e Instrumentos para a regulação de seus efeitos. 
Outros órgãos também participam da cúpula para o desenvolvimento sustentável, dentre eles: a ONU (Organização das Nações Unidas) com os "Objetivos do Miênio"; PNUD (Programa das Nações Unidas para o Desenvolvimento), com o discurso da "Ética"; o Banco Mundial; CNI (Confederação Nacional da Indústria); Agenda 21(Global Brasil e Local); dentre outros.

As principais conferências sobre o Meio Ambiente foram: a Estocolmo (1972)- Conferência das Nações Unidas sobre o Meio Ambiente; Rio de Janeiro (1992) - ECO-92 - Conferência das Nações Unidas sobre o Meio Ambiente e Desenvolvimento; Kyoto (1997) - Cúpula do Clima e Aquecimento Global; Olinda (1999)- Convenção da Desertificação; Haia (2000) - Cúpula do Clima e Aquecimento Global; Bonn (2001) - Cúpula do Clima e Aquecimento Global; e Johanesburgo(2002)-Rio+10.

Diante das considerações feitas sobre as conferências, faz-se um questionamento, de que adiantou tanto quórum se até o momento nada mudou e sim se agravou em relação ao meio ambiente?

\begin{abstract}
A escassez dos recursos não renováveis, as mudanças climáticas, o volume de dejetos industriais e poluentes, ao que se soma a quantidade de lixo doméstico urbano, resultado, dentre outros, da descartabilidade dos produtos impulsionada pela obsolescência programada.Este cenário de exacerbação. Este cenário de exacerbação da "questão ambiental" é revelador da destrutividade inerente ao modo de produção capitalista, cujas crescentes necessidades de produção e acumulação de riqueza, vêm se defrontando com os seus próprios limites de expansão (MOTTA\& SILVA, 2009,p.38).
\end{abstract}

As autorasreconhecem que ao longo dos anos a questão ambiental obteve maior notoriedade e visibilidade tanto na esfera política quanto social, porém, a mesma critica a forma como a questão ambiental vem sendo encarada e exposta para a sociedade.

Embora ganhe espaço e notoriedade, as referências críticas à problemática ambiental se voltammais para a adoção de práticas poupadoras de recursos naturais - de que são exemplos os processos de reciclagem e a utilização de produtos biodegradáveis do que para o enfrentamento do produtivismo e do consumismo que 
marcam as sociedades contemporâneas (MOTTA\& SILVA, 2009, p.38).

A resposta encontrada para a "questão ambiental" não oferece reais possibilidades de alteração do panorama atual de exploração e destruição dos recursos naturais, o "desenvolvimento sustentável" surge como a alternativa para conciliar avanço tecnológico, crescimento econômico e preservação ambiental.

O "desenvolvimento sustentável" surge com um apelo ético e moral transferindo para a sociedade a responsabilidade pela degradação e escassez dos recursos naturais ignorando o fato de ser o atual modo de produção e todo seu processo de crescimento e legitimação o real responsável pela destruição do meio ambiente. O "discurso do desenvolvimento" sustentável traz para a esfera local as "causas" e as "conseqüências" da exploração ambiental ao mesmo tempo em que oferece orientações sobre ações e iniciativas para 0 enfrentamento da questão social.

Outro fato "mascarado" pelo discurso do desenvolvimento sustentável e a contradição entre "sustentabilidade social" e "sustentabilidade ambiental", um exemplo clássico de tal contradição é a reciclagem, grande garota propaganda de tal tendência:

(...) ao mesmo tempo em que contribui para a redução dos resíduos sólidos, este ramo da produção - ancorado no discurso da sustentabilidade e integrado às práticas inscritas no âmbito da responsabilidade social - impulsiona o seu processo de produção mediante a utilização de matérias-primas obtidas com trabalho informal, superexplorado, realizado sob condições subumanas (MOTTA\& SILVA, 2009, p. 39-40).

Com "soluções" como esta o Capital consegue manter, e em alguns casos até aumentar, a produção e a reprodução da "questão ambiental" e administrar a questão social sem comprometer sua dinâmica. Ao longo dos anos as "saídas técnicas" encontradas como supostas soluções para a "questão ambiental" tem se mostrado incapazes de realizar grandes mudanças no quadro geral da degradação ambiental, logo que tais "saídas" não alteram a dinâmica da utilização dos recursos naturais pelo capital. 
Assim, a sustentabilidade ambiental segue uma dinâmica contraditória: constatam-se alguns avanços (medidas de redução da poluição, redução do desperdício na produção, reaproveitamento e reciclagem dos descartes, formação de uma "consciência ambiental"), mas persistem questões essenciais que afetam a reprodução da vida no planeta (MOTTA\& SILVA, 2009, p.41).

A contradição "sustentabilidade ambiental X sustentabilidade social" apresenta outras dimensões ainda mais assustadoras como o agro-negócio e 0 bicombustível que contribuem para o aumento da fome no mundo e a criminalização dos segmentos da sociedade que lutam pela preservação dos recursos naturais.

Após apresentar a postura do sistema capitalista com relação aos recursos naturais e suas conseqüências para a natureza e para a sociedade, a autora afirma sua posição contrária à possibilidade de um real "desenvolvimento sustentável" no atual modo de produção.

\begin{abstract}
O ideário da sustentabilidade implica um conjunto de potencialidades no sentido de criar alternativas à destrutividadegerada pela ordem burguesa. Porém, ao ver-se confinado à dinâmica societária em curso - a um modelo de desenvolvimento para o capital - não indica superação das contradições essenciais evidenciadas na relação sociedade e natureza, o que suprime qualquer margem de dúvidas quanto à incapacidade do sistema resolver as contradições por ele próprio gestadas(MOTTA\& SILVA, 2009, p.43).
\end{abstract}

No texto "A (in)sustentabilidade do Desenvolvimento Sustentável”, a autora também aborda as "questões ambientais" e o desenvolvimento sustentável ou insustentável como ela mesma sugere no título.A resposta para a "questão ambiental" nos anos 70 foi o desenvolvimento sustentável, porém, tal resposta não foi suficiente para alterar a realidade da degradação ambiental.

Silva ainda afirma que o modo de produção capitalista utiliza-se do desenvolvimento sustentável para inocentar-se transmitindo assim a responsabilidade da crise ambiental para sociedade, mais precisamente para os países periféricos, culpabilizando-os pela degradação ambiental e pela desigualdade social, dando ao discurso um enfoque ético e moral.

Mota e Silva citam ainda trechos da Agenda 21 e suas promessas de crescimento propostas pelo desenvolvimento sustentável como mais um 
argumento para facilitar a aceitação das medidas puramente políticas e econômicas pela sociedade como "grande solução" para a questão ambiental e social, já que tais projetos seriam responsáveis por grandes avanços para os países periféricos.

$\mathrm{Na}$ agenda do Desenvolvimento Sustentável, a promoção do crescimento econômico é reiterada, na totalidade dos textos, especialmente para os países periféricos, "um crescimento sustentado e sustentável" (Agenda 21 global, cap. 2, p. 1) que possibilite a satisfação das necessidades da população (SILVA, 2010, p.182).

Mota e Silva citam trechos da Agenda 21 e do Relatório do PNUD 2007/08 não para apoiar o desenvolvimento sustentável, mas sim para evidenciar ainda mais seu caráter imediatista e seus objetivos puramente políticos e econômicos.

O desenvolvimento sustentável como alternativa ante a incontrolabilidade do capital não se constitui em efetivo enfrentamento da "questão ambiental", apesar de que alguns avanços tenham sido obtidos neste campo. (SILVA, 2010, p. 228)

Lowÿ (2000) explicita esta destruição ao relatar que o desenvolvimento das forças produtivas no capitalismo gerou um desequilíbrio e ruptura do metabolismo entre homem e natureza, isto é, destruição dos solos - agricultura devastadora - com a utilização inadequada do mesmo. Essa relação entre homem e natureza é cada vez mais estranhada.

Metabolismo, também segundo Foster eClark (2010) aqui entendido, analogicamente, assim como na biologia - ligação entre matéria e o meio ambiente - relação entre agricultura e sociedade, e que impactos que a agricultura no modo de produção vigente traz para a humanidade como um todo.

E o modo pelo qual se desenvolve a agricultura capitalista engendra uma "falha metabólica". Isto quer dizer que: ao invés da agricultura estar atendendo as necessidades da humanidade, a mesma está funcionando de acordo com as formas de produção capitalista, com um caráter predatório, gerando efeitos sociais catastróficos. Cada vez que o capital avança, a 
destruição da natureza se acelera e que, portanto, desmistifica assim o slogan capitalista da sustentabilidade, não sendo de modo sustentável a forma com que a agricultura capitalista avança.

Diante das considerações feitas acima, como suplantar essa forma de produção e exploração, de forma a manter essa relação harmoniosa entre homem e natureza?

Lowÿ (2004), Foster e Clark (2010) apontam algumas saídas pertinentes. Os ecossocialistas, de acordo com Lowÿ, combatem duramente o sistema capitalista e o seu modo de agir com a natureza e em contrapartida se fundamentam numa sociedade alternativa: o comunismo -, mas um comunismo tendo como foco outro modo de produção menos agressivo e mais reciclável ao meio ambiente. Não uma reciclagem de marketing como é usado co capitalismo, mas uma reciclagem de fato de tudo que será produzido. Mas para isso, no entanto, é preciso, substituir a microrracionalidade do lucro por uma macrorracionalidade social e ecológica, o que exige uma verdadeira mudança de civilização. Isso não é possível sem uma profunda reorientação tecnológica que vise a substituição das fontes atuais de energia por outra fontes, nãopoluentes e renováveis, tais como a energia solar (LOWY, 2000, p. 236).

Ao indicar o triângulo elementar do socialismo, Foster e Clark(2010) também enfatiza outra forma de enxergar a natureza e sua relação com 0 homem. A propriedade privada do capitalismo seria substituída por uma propriedade social, tendo um uso social da natureza e não propriedade sobre a natureza.

E esta produção social seria organizada pelos trabalhadores, pois são eles que produzem a riqueza socialmente através da regulação racional do metabolismo entre seres humanos e natureza pelos produtores associados.

Com tudo isso teria uma satisfação das necessidades comunais anseios em comum - não só das gerações atuais, mas tendo continuidade para as próximas gerações. 
Realmente a luta pela preservação da natureza aparece como um importante ponto de pauta para todos aqueles que acreditam num projeto de desenvolvimento para o país, porém o avanço tecnológico capitalista degrada planeta a tal ponto que o destrói aos poucos. O alcance da degradação do capitalismo não é local, e sim global, e é de forma irreversível. O capitalismo tem características próprias a seu sistema, e o mesmo se torna incompatível com o desenvolvimento sustentável do planeta, pois ao explorar a natureza, o capitalista explora também a força de trabalho da mesma natureza seu objeto de trabalho, ou seja, associação entre exploração do proletariado e da natureza.

\section{CONCLUSÃO}

Diante do exposto supracitado, percebe-se que o planeta já não suporta mais a sobrevivência de um sistema que empurra milhões de pessoas para a miséria, que polui a água e o solo com toneladas de agrotóxicos e fertilizantes químicos, que sem alternativas incham cada vez mais as favelas dos centros urbanos. Um sistema que causa a corrupção e a violência.

O sistema capitalista é o principal causador de tanta destruição, que vem representado pelas grandes empresas transnacionais e nacionais, pelas empreiteiras que pretendem construir hidrelétricas no meio da Amazônia ou pelas construtoras com os olhos voltados para o lucro fácil de construir em uma área visada pela especulação imobiliária, não se importando, que para isso seja preciso acabar com nascentes de água doce, matar espécies nativas em perigo de extinção ou expulsar vinte mil moradores do lugar em que construíram suas vidas. A única saída que se coloca para a humanidade diante da ameaça de sua própria destruição é um projeto construído pelo povo.

Destarte, as contradições inerentes ao modo de produção capitalista e seu modelo de desenvolvimento sustentável não podem superar e resolver as contradições por ele mesmo elucidadas na relação natureza e sociedade. 
Esse contexto ganha tamanho e proporção numa sociedade de cunho consumista acelerado, onde o "ter" se sobrepõe ao "ser". Por isso quanto mais você tem, mais é valorizado exaltado nesse tipo de sociedade. Mas uma pergunta paira no ar: até aonde a natureza resiste neste planeta de descartáveis?

Sua estrutura "grita" os últimos sinais de esgotamento e reserva. E é preciso refletir e analisar o modo de funcionamento da sociedade atual para vislumbrar uma possível superação da mesma; é preciso outro tipo de relação social entre os homens, e entre homem e natureza para alcançar uma relação mais sustentável economicamente, socialmente, e, principalmente, ecologicamente.

\section{REFERÊNCIAS BIBLIOGRÁFICAS}

FOSTER, John Bellamy \& CLARK, Brett. A dialética do metabolismo socioecológico: Marx, Mészáros e os limites absolutos do capital. In.: Revista Margem Esquerda. São Paulo:

Boitempo,n $14,2010$.

LOWY, Michael. Marxismo, modernidade e utopia. São Paulo: Xamã, 2000. (De Marx ao Ecossocialismo). 2004. . Marx, Engels e a ecologia. In.: Revista Margem Esquerda. São Paulo: Boitempo, n³,

MOTA, Ana Elizabete \& DAS GRAÇAS E SILVA, Maria. A questão ambiental e o contraditório discurso da sustentabilidade. In Revista Praia Vermelha: vol. 19, n², Rio de Janeiro: UFRJ. ESS, 2009.

SILVA, Maria das Graças. A (in)sustentabilidade do Desenvolvimento Sustentável. São Paulo: Cortez, 2010.

Recebido: 30/08/2014

Aprovado: 25/11/2014 